\title{
15 To care or not to care? What have we learned from COVID-19 about our attitudes towards older adults?
}

\author{
Linda Garcia, Louise Bélanger-Hardy, \\ and Martine Lagacé
}

The COVID-19 pandemic has had tremendous impact on how we care about the wellbeing of others, especially older adults. The chapter explores how societal attitudes, including ageism, have been exacerbated by both our personal and institutional management of COVID-19 and subsequent caring of and for older adults. The authors reflect on the notion of caring in different contexts: intergenerational perceptions, the choices made in addressing the spread of the pandemic to longterm care settings, the role of non-professional caregivers and finally, caring from a systemic governmental perspective. The chapter then discusses the extent to which lessons can be learned regarding the desire to care for one another using Tronto's seminal work on the ethics of care (Tronto, 1998). Factors such as rapid deconfinement measures and the public behaviours worldwide suggest that effecting meaningful transformation within society will require a profound reflection on caring and the process of aging as we move out of the pandemic.

The COVID-19 pandemic has unveiled and continues to unveil some of humanity's finest moments of empathy and solidarity. Unfortunately, the crisis has revealed the darker side of human conduct as well. Earlier in the pandemic, in speaking about the COVID-19 worldwide, Antonio Gutierres, Secretary General of the United Nations noted that "we see the disproportionate effects on certain communities, the rise of hate speech, the targeting of vulnerable groups, and the risks of heavy-handed security responses undermining the health response" (Guiterres, 2020). As we move towards the end of this pandemic, we must learn from our experiences and reflect on the societies we wish to build in the future.

The Secretary General reminded us that the ethical decisions made during the crisis are intricately tied to matters of human rights. Indeed, as store fronts and communities in Canada displayed signs saying, "we're all in this together," public authorities made decisions about freedom of movement, access to health care, and composition of social circles. Those decisions

DOI: $10.4324 / \mathrm{b} 22774-20$ 
reveal much about how we really care about one another, while significantly challenging the perception that we are really "all in this together."

One of the so-called vulnerable groups targeted at the first signs of the virus were older adults. The significant impact of COVID-19 on individuals with multiple chronic conditions, of which a significant number are older, has been well documented. But, by far, what has left the most lasting impression on our communities was the disproportionate impact of the virus on health and consequently on the number of deaths in the older age group. As the numbers of cases of illness amongst older adults increased, decisions to confine these adults to their homes also grew, without full recognition of the impact this might have on their need to be connected to others. Many countries imposed increasingly restrictive demands to quarantine all groups as they contained the spread of the virus. As a less digital savvy segment of our populations, older adults were further isolated. The image of a vulnerable population in need of help from its fellow citizens quickly emerged. In other words, a discourse of protection of older adults began to materialize.

While this bleak situation was unfolding, a parallel trend occurred worldwide. Some citizens began showing signs of not caring about the plight of older adults. Advocacy groups and scholars documented references to hateful comments on social media about the impact of COVID-19 on older adults, with terms such as \#boomerremover circulating widely on the Internet. As well, at times, generations appeared pitted against each other regarding the spread of the disease. As the crisis slowed down, many citizens ignored deconfinement measures and exhibited a lack of concern for the impact of their conduct on vulnerable groups. An important point to note is that older adults themselves sometime exhibited similar attitudes towards the very aged, the "super seniors" or "vulnerable and helpless" older adults. Some members of both younger and older generations apparently believed that the "we" in "we are all in this together" did not concern "them."

Explaining this type of behaviour is difficult and, while addressing this complexity goes beyond the aim of this chapter, we do argue that the current health crisis has brought to the forefront what appears to be an absence of "caring for the other." This lack of caring has not only occurred at the individual level but more broadly as well. Indeed, in Canada at least, the dismal situation in long-term care homes during the COVID-19 crisis, leading to over $80 \%$ of the COVID-19 related deaths in the country (Hsu et al., 2020), has unveiled a number of serious ongoing problems within the long term care system. The pandemic has simply shined a light on issues that have existed for a long time.

In this chapter, we argue that the COVID-19 pandemic has had a significant impact on our desire and ability to care, and that older adults have been disproportionately affected by society's ineptness at caring, especially in western, high income countries. We suggest as well that our attitudes can be explained, at least in part, through the phenomenon of ageism. Negative 
conceptions of age influence how society values older adults but also, more generally, how we value care.

The first part of the chapter defines and illustrates the notion of ageism. We then examine the concept of care, relying on some of the contributions of scholars such as Tronto and others. We focus specifically on four dimensions of care: between generations, towards the very vulnerable, towards caregivers, and by institutions and governments. We conclude by suggesting that, in the months, and perhaps years to come, our collective and individual efforts to contain the consequences of the COVID-19 pandemic must include genuine compassion and care not only for older adults but towards each other as well.

\section{The unveiling of ageist attitudes}

Within Western culture, the process of ageing and the status of old age are often negatively depicted (Trincaz \& Puijalon, 2010). The fact of growing older is largely associated with physical and psychological decline. Robert N. Butler was amongst the first researchers to study the profound "malaise" expressed by many individuals towards ageing and old age, conceptualizing it as "ageism" (Butler, 1975). Precisely, ageism refers to the "complex, often negative construction of old age, which takes place at the individual and the societal level" (Ayalon \& Tesh-Römer, 2018, p. 3). Ageism underlies a cognitive, affective, and behavioral component, namely (a) negative stereotypes associated with ageing and old age (vulnerability, uselessness, helplessness, lack of autonomy, etc.); (b) prejudice, i.e., negative emotions manifested towards older adults, and (c) discriminatory aged-based behaviors, such as avoidance, negligence, and abuse of older adults (Global Report on Ageism, 2021; Ayalon et al., 2019). Importantly, ageism may be manifested in a subtle way such as patronizing and over-accommodating language as well as overprotective behaviors. Although subtle ageism, also called "compassionate ageism," may stem from a well-intentioned desire to help, it still conveys the predominant perception of older adults as frail, vulnerable, and helpless individuals. Ageism may also take a hostile form such as physical, financial, and verbal abuse. As stated previously, the discourse around older adults conveyed on some social media platforms at the very beginning of the pandemic - whereby the COVID-19 virus translated in the hateful hashtag "boomer remover" - undoubtedly echoes overt and hostile ageism.

Ageism permeates numerous social arenas and is particularly prevalent in health care contexts. Indeed, older patients can be the target of ageism on the part of health care providers - even if manifested in a subtle and well-intentioned way. This is so simply because care providers often perceive older adults as psychologically and physically fragile due to their age. For example, relying on secondary data stemming from surveys and clinical observations, Ouchida and Lachs (2015) argue that during medical encounters, care providers communicate - verbally and non-verbally - in different 
ways with older adults than with younger adults. Specifically, physicians are more impatient and less engaged with older patients. They are also less likely to respond to the issues they raise. Therefore, our very ability to care for older adults is expressed by how we communicate "with" them and how we speak "about" older persons. In the face of a pandemic, and when challenged with decisions regarding the care of patients, it is easy to see that communications that are ageist in their approach can be detrimental to the wellbeing of older adults.

Along the same lines, a substantial number of scholarly studies have documented the use of patronizing language during medical encounters with older patients. The source of ageist communication seems to lie with care providers who may have subconscious misconceptions and stereotypes that older patients are frail, helpless, irritable, and dependent (Atkinson \& Sloan, 2016).

In sum, decades of studies on ageism demonstrate that this form of discrimination is prevalent in many facets of Western culture, for example, work, media, legal systems, and healthcare (Global Report on Ageism, 2021). The negative impact of ageism on older adults is well-documented, increasing physical problems and feelings of social isolation while lowering self-esteem and self-efficiency. Notwithstanding the prevalence and negative impact of ageism, it remains one the most socially condoned form of discrimination. Under-reported cases of abuse and neglect in long-term care homes speak volumes on the prevalence of ageism. As will be argued below in this chapter, the pandemic seems to have exacerbated long time anchored ageist attitudes towards older adults, acting as a magnifying glass in terms of ageism's negative outcomes. This in turn appears to be linked to the absence of a "caring attitude" towards older adults.

\section{Caring in an ageist society}

At the time of the writing of this chapter, the world was still battling the repercussions of COVID-19. As countries struggle with their decisions about whether to open up borders, re-stimulate their economies, support their citizens, and guide them in the best public health response possible, scholars are documenting the more subtle impacts of this pandemic, including social isolation. For some older adults, this has contributed to the phenomenon of age digital divide (Ramsetti \& Adams, 2020).

The remedies for social isolation necessarily include contact with other people and this was severely impacted by containment measures requiring social distancing. Furthermore, academics working in the field of ageing have acknowledged for some time that older adults, in high income countries at least, are at disproportionate risk of social isolation. Should we not, then, be reflecting on how concerned we really are about the care others receive during a disruptive situation such as a pandemic? 
Tronto $(1993,1998,2010)$ and Tronto and Fisher (1990) have written extensively on the ethics of care. In their words, Tronto and Fisher (1990, p. 40) suggest that caring be viewed

as a species activity that includes everything that we do to maintain, continue, and repair our "world" so that we can live in it as well as possible. That world includes our bodies, ourselves, and our environment, all of which we seek to interweave in a complex, life-sustaining web.

Tronto and Fisher's conception of care can often be at odds with the individualistic approach espoused by Western societies. Care presupposes a concern for the effect we have on each other and requires an ethical and moral duty to respond to each other's needs. During the ongoing pandemic, there have been instances where citizens of all ages have shown concern for others and where caring for one another has been at the forefront of individual and community initiatives. However, as the pandemic and its aftermath unfold, we unfortunately continue to see significant evidence of lack of concern for others. The challenges of "caring" occur in a number of contexts including intergenerational interactions, very vulnerable populations, relations with caregivers and finally, public authorities' interventions before, during and after the pandemic.

\section{Caring about other generations}

The public discourse on ageing and older adults - whether conveyed by the media, the government, or the research community - shapes or at least partly shapes individual perceptions and personal experiences of ageing. The process is one of normalization and internalization of social representations of ageing within a person's scheme of beliefs (Renaud et al., 2006); in turn, the process influences how members of different generations perceive and interact with one another.

Within the intergenerational discourse, many studies have concluded that representations of ageing and older adults are mostly negative and polarized (Lagacé, Laplante \& Davignon, 2011). On the one hand, the ageing process is depicted either as a social and economic burden whereby older adults are associated with rising health-care costs, especially older adults living in long-term care facilities. On the other hand, studies point to a mainstream public discourse that praises older adults who manage to counter signs of ageing and embody images of youthfulness. In both cases, as argued by scholars, such polarized representations are fueling ageism at the inter and intra generational levels (Rozanova, Miller \& Wetle, 2016). In the former, negative, and homogenized views of ageing may deepen the gap between younger and older generations, while in the latter case, "false positive" views of ageing may create a divide amongst older adults themselves. 
The COVID-19 pandemic sheds further light on representations of ageing and older adults in the public discourse and the ways younger and older generations perceive and care for one another. Studies conducted at the very beginning of the crisis are quite revealing to this effect, pointing to an exacerbation of ageist stereotypes. For example, Jimenez-Sotomayor, GomezMoreno, and Soto-Perez-de-Celis' (2020) content analysis of the portrayal of older adults in social media shows that almost a quarter of 362 tweets posted during the period of March 12 to 21, 2020 reflected offensive and denigrating content towards older adults. Mainstream media portrayed older adults as "vulnerable" individuals needing to be protected from the virus and its impact (Fraser et al., 2020). It goes without saying that this vulnerability label (applied solely on the basis of age, i.e. persons aged 65 years old or more) not only reinforces ageist stereotypes but positions older adults as victims that cannot take part in a process of collective resilience against the virus (O’Sullivan et al., 2014).

\section{Caring about the most vulnerable}

Older adults living in long-term care homes (LTCH) constitute some of the most vulnerable citizens affected by the COVID-19 pandemic. Many of the residents in LTCH are part of the "oldest old." For example, the Ontario Long-Term Care Association (OLTA), the largest association of its kind in Canada, confirms in one of its recent reports that $82 \%$ of residents (public and private facilities combined) are over 75 years of age and $55 \%$ are over 85 years of age (OLTA, 2019). These statistics, representative of LTCH residents across Canada, are unlike the demographic make-up of residents of 30 or 40 years ago, when residents were younger. Furthermore, due to successful "ageing at home" programs, older adults in LTCH live with more complex and chronic health conditions than yesteryear thus presenting the staff with an increasingly older population with complex needs and in need of increasingly specialized care.

In fact, beyond age, the presence and nature of two or more chronic health problems, i.e., comorbidity, increases the vulnerability of people living in LTCH. It continues to be clear, as it was when COVID-19 presented itself in China and Italy, that those most susceptible to the coronavirus are those with multiple health conditions, particularly diabetes, chronic obstructive pulmonary disease, and cardiac conditions. Why, in Canada, did we not anticipate and, above all, plan for the eventuality of a crisis involving older adults with such conditions?

We wonder as well why the push to provide sufficient personal protective equipment to the staff was not prioritized as it had been when the focus was on acute care. When the pandemic was declared in mid-March 2020, protective measures, including masks and other personal protective equipment, were not available in sufficient numbers. The lack of planning and preventative measures in LTCH must be decried when authorities knew that these 
places were highly vulnerable to the spread of the virus and that the disease could wreak havoc on residents.

One feature of LTCH in Canada is that personal support workers (PSW) who care for the residents' most basic needs and activities of daily living have low wages and their precarious situation leads them to work in more than one LTCH. One of the most publicized issues of the COVID-19 pandemic was the retention of PSWs who, in some cases, left their workplaces due to burnout or inadequate protective equipment. The absence of several employees forced those who remained to continue working in conditions that were not only very difficult, but also more conducive to the further contamination of residents, as employees moved from floor to floor or from LTCH to LTCH. We wonder how this could have been allowed since authorities knew full well, from the outset of the pandemic in Canada, that the COVID-19 virus was highly contagious and could be transmitted by asymptomatic individuals.

In the end, the health crisis caused by COVID-19 exposed a disturbing reality: many of our most vulnerable older adults live in environments where health providers are overworked, poorly paid, and where their specialized skills are neither recognized nor valued. Of note, in Canada, PSWs are not a self-regulated, autonomous profession. However, this may well change, at least in some provinces or territories. For instance, following the worst of the health crisis, the province of Ontario passed legislation to provide a non-compulsory regulatory scheme for PSWs working in a number of settings including LTCH. One of the law's stated objective is to promote safe, competent, ethical and high-quality health and supportive care services and to develop codes of ethics (Advancing Oversight and Planning in Ontario's Health System Act, 2021). This type of measure could assist in ensuring better care provided governments take concrete measures to improve the PSWs working conditions - something that the legislation fails to address.

\section{Caring about caregivers}

The importance of understanding the role of unpaid care has been heightened by the COVID-19 pandemic. About 8 million Canadians provide care to a relative or a friend (Statistics Canada, 2018), comprising more than $80 \%$ of the care needed and contributing to over 25 billion dollars in unpaid work (Hollander, Liu \& Chappell, 2009). This is also not limited to Canada. The demographic change is so great worldwide that no country in the world, whether low-, mid- or high-income will be able to adjust without supporting a strong informal caregiver base. The complexity and importance of care have never been clearer. Faced with the added burden of COVID-19, family and friends are tested as they seek to provide support despite reduced, withdrawn or canceled community respite services and home care.

Yet, while there have been numerous news reports, preliminary studies, commentaries, and political speeches about the effect of the pandemic, very 
few have addressed the needs of this very significant portion of our population. We have known for years that those who care for older adults, especially older adults with dementia, need help from others to carry on (Queluz et al., 2020). We know as well that these needs are often unmet or ignored by formal health care workers. While caregivers of older adults are not homogenous in their needs, all of them require a form of relief from caregiving duties and time for themselves. Queluz et al. (2020, p. 48) found evidence that caregivers' inability to take care of themselves was "directly related to lack of help from others."

The data on the pandemic's long-term impact on caregivers remains to be collected, but we can reasonably presume that results will confirm this impact was significant, especially since we know the experience of caregiving often has negative consequences on caregivers' health and wellbeing (Schulz et al., 2020). Some caregivers of older adults are now left to care for their loved ones with no additional care and support from others, whether they be paid caregivers or family, friends, or volunteers. As well, these caregivers must deal with the effects of the COVID-19 pandemic on their own lives. Greenberg, Wallick and Brown (2020) point out that it is difficult for these caregivers to find down time and respite from the demands placed on them.

Studying a group of caregivers living in India, Vaitheswaran et al. (2020) have described the increased demands made on caregivers of people with dementia during the crisis. This group of older adults may not fully understand the COVID-19 situation, leaving it up to caregivers to manage public health recommendations in addition to dealing with the care they habitually provide. With the pandemic adding to other demands, Vaitheswaran et al. (2020) report additional concerns from caregivers related to issues such as the protection of loved one from disease, managing isolation with older adults who do not understand the situation, and changes in routines which are known to impact some of the behaviours expressed by the unmet needs of the care receiver with dementia.

Fortunately, there has been some level of social support given to older adults during the COVID-19 pandemic and this has filtered to caregivers as well. Technology has helped caregivers who could afford it to stay connected, essential groceries and needs have been provided by kind family members, neighbours and volunteers, and some informal support has been given through advocacy groups through online means and visits from a distance (Lightfoot \& Moone, 2020). However, at the time of the writing of this chapter, we still struggle to manage the new cases of COVID-19 and we continue to push aside the needs of those caring for older adults. As has been noted above, we rely extensively on these individuals to make sure that older adults' needs are met. If not met prior to COVID-19, there is certainly no chance that COVID-19 helped matters. The forgotten group of caregivers of older adults will most definitely need care post pandemic. 
Caring from a systemic/governmental perspective

The COVID-19 pandemic's disproportionate impact on older adults living in long-term care points to the need for consideration of the role played by governments and by care institutions in managing the crisis. Clearly, in Canada at least, the pandemic has revealed the inadequacies and weaknesses of existing networks and systems. While post-SARS reports led to a number of reforms in Canada, including the restructuring of public health institutions (Fierlbeck \& Hardcastle, 2020), little consideration has been given to pandemic management and the older population. While this may be explained by the fact that both the SARS and 2009 H1N1 outbreaks did not target older adults, we nonetheless believe it is fair to ask why preparedness plans failed to include a part of the population more susceptible to health challenges and comorbidities.

Despite foreseeable demographic changes marked by an ageing population and an increase in the number of frail older people, political and social choices regarding the most vulnerable older adults have had serious consequences during the pandemic. Despite clear indications that many of the problems were well-known for decades, the proper steps to address the risks in caring facilities were not taken early enough, with devastating results. For example, in Ontario, Canada's most populous province, the Canadian Armed Forces (CAF) were called in to assist residents in some LTCH. After a number of weeks, the CAF Joint Task Force Central rendered public a 15-page report (Mialkowski, 2020) based on the observations of its military personnel in the five Ontario LTCH deemed by the province to have required the most support. The report revealed severe instances of regulatory violations and neglect, spanning from non-adherence or non-existence of policies (ex: lack and/or improper use of personal protective equipment (PPE) by staff, use of expired medication, absence or improper charting), inadequate resources including trained staff and medical supplies, poor or little training, deficiencies in infrastructure (ex: insects, inadequate disinfection), concerns about standards of care (ex: poor catheter hygiene, poor or inexistent treatment of pressure ulcers), general neglect (and finally, violence (ex. aggressiveness, forceful feeding and degrading comments about residents). In the neighbouring province, Quebec, the situation in some homes has been dire, with a large number of deaths, severe worker shortages and insufficient PPE. In one particular home, the care was reported as substandard, with residents not adequately fed, and staff deserting the home in the middle of the outbreak.

While one must recognize that not all LTCH in Canada are deficient to the extent described in the Joint Task Force report, we suggest that the information in such reports does not align in any way with a caring society, caring institutions, or caring governments.

But are governments and public bodies in the business of "caring"? The current literature suggests that they should be and highlights the need to 
reflect on how care ethics can be applied to institutions and social policy. For instance, Stensöta (2015, p. 185) notes that "ethics of care" has traditionally been discussed in the context of care-based settings but that, increasingly, the notion is relied on "to dissect the current arrangement of care provision (or rather non-care provision) in policies and administrative procedures." For her part, FitzGerald (2020, p. 255) argues that care ethics in its "political" dimension "provides a more fruitful path forward if our concern is reaching the full radical transformative potential of an ethics of care." To this end, she "imagines" a governmental Department of Care working "towards new distributions of responsibility for care through democratic processes" (p. 257) and

both caregivers (whether professional or otherwise) and care receivers would need to be consulted on an ongoing basis; each programme would have to facilitate the exchange of ideas, concerns, and feedback related to the ways in which the programme is (re)structuring the caring relation.

While the creation of such a governmental department is not imminent (not to say unrealistic), the suggestion makes us reflect on the importance and relevance of "care" in transforming all facets of our societies.

\section{Caring now and in the future}

As countries move towards deconfinement and as our citizens learn to adapt to life during a pandemic, we must start to reflect on the lessons learned and on our approach to caring for one another. Did we learn anything from the COVID-19 pandemic so far? Gary and Berlinger (2020) reflect on this very question. In their commentary, they rely on Tronto's (1993) conception of care to highlight the undervalued status of care workers in our society. This attitude shows that we must reframe the importance given to care and we must see our commitment to caring for older adults as a societal responsibility. Gary and Berlinger (2020) consider the components of the ethics of care concept to examine how societies might respond to the needs of their members rather than neglecting them in moments of hardship. Undeniably, Tronto and Fisher's (1990) four phases of care can help us think about how we have approached care for one another during this pandemic and how we might repair our world as we move forward.

The first phase of the ethics of care, caring about, involves recognizing and listening to the needs of others. Clearly, as noted above, this has not always been the case during the current pandemic. For example, when, during the period of deconfinement, individuals gather in large groups, refuse to follow directives and, in extreme cases, deny the very existence of the pandemic, concluding that some members of society do not "care about" others, 
more vulnerable than they are, is logical. Notwithstanding the exemplary initiatives from many groups, mainly advocacy and volunteer groups worldwide, one seriously questions our collective and individual ability to truly care about the older members of our society.

The second phase identified by Tronto and Fisher, caring for, refers to our sense of responsibility in addressing identified needs. As we have seen in the examples above, we have failed as a society to recognize our responsibility towards older adults in LTCH. Despite having known of the challenges and the demographics in LTCH for many years, we were incomprehensively unprepared for outbreaks in settings where individuals were particularly vulnerable. Only a few months into the pandemic, and after a significant loss of life, did governments step up to mitigate the devastating consequences of the pandemic on LTCH residents.

The third phase of the ethics of care, care giving, refers to the actual action of giving care. Once a need is identified acknowledged action must be taken. Have we, as a society, failed in this regard as well? In large part, we believe we have. As described above, an important segment of society has been left without caregivers, without protection and without resources to address pressing needs. Numerous reports have described how older citizens were left to die alone. From a practical perspective, the tools for caring (personal protection equipment, human resources etc.) were slow in coming (Faghanipour, Monteverde \& Peter, 2020). Caregivers have had to wait a long time before getting help from advocacy groups and others, leaving several care recipients to their own devices. Governments have eventually provided help to LTCH but they have failed to consider the integration of families and volunteers in the circle of care.

The final phase of Tronto and Fisher's ethics of care is care receiving. In this final and very important phase, ethical care is measured as a function of how well the actions respond to the needs of the care receiver. At this point of the pandemic, it is safe to say that most of the care receiving for older adults has been related to the care of the physical self. In other words, the need to live was addressed quickly, but it can be argued that even this need was not met and continues to not being met in certain parts of the world. While older adults are now receiving attention in $\mathrm{LTCH}$, it is unclear whether the caregiving meets the needs of the care receivers (Tronto, 2010). More studies will be required to assess how care receivers are faring.

\section{For further discussion...}

The COVID-19 pandemic has shown that we are as ageist as ever, that we like to blame others for what is happening and that we really were not "all in this together." Older adults are not blameless when it comes to lack of care. As noted, ageist attitudes are not the product of younger generations alone (Global Report on Ageism, 2021). Just like their younger counterparts, many older adults are guilty of not heeding to public health directives. Studies 
have shown that they prefer not to be confronted with their older selves. They can be as guilty of neglecting the needs of older adults as individuals in younger age groups. In the end, we are all in this together when it comes to our collective failure to care.

Unfortunately, there is some indication that we have many challenges ahead of us. Progressive deconfinement in many countries has led to a disregard for public health guidelines, demonstrations worldwide on the requirements needed to keep everyone safe, silence from all of us, including the boomer generation, on what has happened to older adults. We are creating societies where meeting our own needs overrides everyone else's; we make judgments based exclusively on age and we pit generations against each other. Surely this is not the ethical world in which we hope to live.

The current pandemic will end one day. What will happen in LTCH once the worst is over? How will we speak of other generations? What will happen to caregivers and what steps will our governments take to make sure older adults are respected and recognized as contributing members of our society? We must recognize that structural, organizational, administrative, and financial improvements could very well lay the groundwork for better caring of others (especially those in great need). However, we suggest that such measures will not be sufficient if they are not supported by a profound social and political rethinking of the values we hold about ageing and older persons. The first step implies an acknowledgment of the prevalence of ageism and the recognition that the phenomenon affects our ability to truly care for others. Reflecting on our value system in the face of ageing and questioning ageism are colossal tasks, but change is achievable. We propose an upstream measure. Since ageism is a matter of representations that are acquired early in life, we believe that awareness of ageist prejudices and discrimination should be integrated to the educational pathway of the youngest members of society. Moreover, in the workplace, and particularly in long-term care settings, awareness of ageism should be a sine qua non condition of employment for caregivers, managers, and residents alike. We suggest that raising awareness of ageism through education and training would be the starting point for a change in our value system.

However, in order to bring about this change in values, it is necessary to go one step further and put in place political and legal mechanisms that can serve as a springboard for the development of initiatives to address ageism. This is the objective behind, for example, an international convention protecting the rights of older persons. This instrument would give older adults a voice, choices and, de facto, the right to demand that social actors respect their person and their health. Older adults are as diverse as any other age group. A convention is not meant to isolate them from other social groups. Rather, such an instrument aims to protect them from society's lack of recognition, lack of responsibility, lack of action and lack of effort to adequately meet their needs. A UN Convention on the Rights of Older Persons 
would give an additional tool to argue that older adults do indeed have a right to be cared about, cared for, and be both care givers and care receivers.

We are currently living in situations where we must continuously decide how to act, whether to put on a mask, to visit, to support others. As well, as Schimmenti, Billieux and Starcevic (2020) eloquently describe, the COVID-19 pandemic has created fear: fear of the virus, fear for and of loved ones, and fear to make decisions. All these fears are age neutral. And, in this sense at least, we are indeed all in this together. We just need to care that we are.

\section{References}

Atkinson, J.L., \& Sloan, R.G. (2016). Exploring the Impact of Age, Race, and Stereotypes on Perceptions of Language Performance and Patronizing Speech, Journal of Language and Social Psychology, 36(3), 287-305. https://doi-org.proxy.bib. uottawa.ca/10.1177/0261927X16662967

Ayalon, L., \& Tesh-Römer, C. (2018). Contemporary Perspectives on Ageism, International Perspectives on Aging Book Series, 19, 564. https://doi.org/10.1007/ 978-3-319-73820-8

Ayalon, L., Dolberg, P., Mikulionienè, S., Perek-Białas, J., Rapolienė, G., Stypinska, J., Willińska, M., \& de la Fuente-Núñez, V. (2019). A Systematic Review of Existing Ageism Scales, Ageing Research Reviews, 54. https://doi.org/10.1016/ j.arr.2019.100919

Butler, R.N. (1975). Why Survive? Being Old in America (p. 496). Manhattan, NY: Harper \& Row.

Faghanipour, S., Monteverde, S., \& Peter, E. (2020). COVID-19-Related Deaths in Long-Term Care: The Moral Failure to Care and Prepare, Nursing Ethics, 27(5), 1171-1173. https://doi.org/10.1177/0969733020939667

Fierlbeck, K., \& Hardcastle, L. (2020) Have the Post-SARS Reforms Prepared Us for COVID-19? Mapping the Institutional Landscape. In C. Flood, V. MacDonnell, J. Philpott, S. Thériault \& S. Venkatapuram (Eds) Vulnerable - The Law, Policy and Ethics of COVID-19 (pp. 31-48). Ottawa: University of Ottawa Press.

FitzGerald, M. (2020). Reimagining Government with the Ethics of Care: A Department of Care, Ethics and Social Welfare, 14(3), 248-265, https://doi.org/ 10.1080/17496535.2020.1746819

Fraser, S., Lagacé, M., Bongué, B., Ndeye, N., Guyot, J., Bechard, L., Garcia, L., Taler, V., CCNA Social Inclusion and Stigma Working Group, Adam, S., Beaulieu, M., Bergeron, C.D., Boudjemadi, V., Desmette, D., Donizzetti, A.R., Éthier, S., Garon, S., Gillis, M., Levasseur, M., Lortie-Lussier, M., ... Tougas, F. (2020). Ageism and COVID-19: What Does Our Society's Response Say About Us? Age and Ageing, 49(5), 692-695. https://doi.org/10.1093/ageing/afaa097

Gary, M., \& Berlinger, N. (2020, May 1). Interdependent Citizens: The Ethics of Care in Pandemic Recovery. Hastings Center Report. New York: John Wiley and Sons Inc. https://doi.org/10.1002/hast.1134

Greenberg, N.E., Wallick, A., \& Brown, L.M. (2020). Impact of COVID-19 Pandemic Restrictions on Community-Dwelling Caregivers and Persons with Dementia, Psychological Trauma, 12(S1), S220-S221. https://doi.org/10.1037/tra0000793 
Guitteres, A. (2020). We Are All in This Together: Human Rights and COVID-19 Response and Recovery. https://www.un.org/en/un-coronavirus-communications-team/ we-are-all-together-human-rights-and-covid-19-response-and

Hollander, M.J, Liu, G., \& Chappell, N. (2009). Who Cares and How Much? Healthcare Quarterly, 12(2), 42-49.

Hsu, A.T., Lane, N.E., Sinha, S.K., Dunning, J., Dhuper, M., Kahiel, Z., \& Sveistrup, H. (2020, June 4) Report: Understanding the Impact of COVID-19 on Residents of Canada's Long-Term Care Homes-Ongoing Challenges and Policy Responses. Article in LTCcovid.org, International Long-Term Care Policy Network, CPEC-LSE.

Jimenez-Sotomayor, M.R., Gomez-Moreno, C., \& Soto-Perez-de-Celis, E. (2020). Coronavirus, Ageism, and Twitter: An Evaluation of Tweets about Older Adults and COVID-19, Journal of the American Geriatrics Society, 68, 1661-1665. https:// doi.org/10.1111/jgs.16508

Lagacé, M., Laplante, J., \& Davignon, A. (2011). Construction sociale du vieillir dans les médias écrits canadiens: De la lourdeur de la vulnérabilité à l'insoutenable légèreté de l'être, Communication et Organisation, 40, 87-102. https://doi. org/10.4000/communicationorganisation.3553

Lightfoot, E., \& Moone, R.P. (2020) Caregiving in Times of Uncertainty: Helping Adult Children of Aging Parents Find Support during the COVID-19 Outbreak, Journal of Gerontological Social Work. https://doi.org/10.1080/01634372.2020. 1769793

Mialkowski, C.J.J. (2020) OP LASER-Joint Task Force Central Observations in Long Term Care Facilities in Ontario, Canadian Armed Forces Report, https://s3.amazonaws.com/zweb-s3.uploads/carp/2020/05/OP-LASER-JTFCObservations-in-LTCF-in-ON.pdf

OLTCA: Ontario Long Term Care Association. (2019). This Is Long-Term Care 2019. Ontario Long-Term Care Association. https://www.oltca.com/OLTCA/ Documents/Reports/TILTC2019web.pdf

O’Sullivan, T.L., Kuziemsky, C.E., Corneil, W., Lemyre, L., \& Franco, Z. (2014). The EnRiCH Community Resilience Framework for High-Risk Populations, PLoS Currents. DOI: 10.1371/currents.dis.11381147bd5e89e38e78434a732f17db

Ouchida, K.M., \& Lachs, M.S. (2015) Not for Doctors Only: Ageism in Healthcare. Generations (Electronic Edition). https://www.asaging.org/blog/ not-doctors-only-ageism-healthcare

Queluz, F., Kervin, E., Wozney, L., Fancey, P., McGrath, P.J., \& Keefe, J. (2020) Understanding the Needs of Caregivers of Persons with Dementia: A Scoping Review, International Psychogeriatrics, 32(1) 35-52. DOI: 10.1017/ S1041610219000243

Renaud, L., Bouchard, C., Caron-Bouchard, M., Dubé, L., Maisonneuve, D., \& Mongeau, L. (2006). A Model of Mechanisms Underlying the Influence of Media on Health Behaviour Norms, Canadian Journal of Public Health, 97(2), 149-152. https://www.jstor.org/stable/41994707

Rozanova, J., Miller, E., \& Wetle, T. (2016). Depictions of Nursing Homes Residents in US Newspapers: Successful Ageing Versus Frailty, Ageing and Society, 36(1), 17-41. doi: 10.1017/S0144686X14000907

Schimmenti, A., Billieux, J., \& Starcevic, V. (2020). The Four Horsemen of Fear: An Integrated Model of Understanding Fear Experiences during the COVID-19 Pandemic, Clinical Neuropsychiatry, 17, 2, 41-45. https://doi.org/10.36131/CN20200202 
Schulz, R., Beach, S.R., Czaja, S.J, Martire, L.M., \& Monin, J.K. (2020). Family Caregiving for Older Adults, Annual Review of Psychology, 71, 635-59, https://10.1146/annurev-psych-010419-050754

Statistics Canada. (2018). Caregivers in Canada, 2018. https://www150.statcan.gc.ca/ n1/daily-quotidien/200108/dq200108a-eng.htm

Stensöta, H.O. (2015). Public Ethics of Care: A General Public Ethics. Ethics and Social Welfare, 9(2), 183-200.

Trincaz, J., \& Puijalon, B. (2010). Vieillir en terre hostile, In S. Carbonnelle (Ed), Penser les vieillesses. Regards sociologiques et anthropologiques sur l'avancée en âge (pp. 21-36). Paris: Éditions Seli Arslan.

Tronto, J. (1993). Moral Boundaries: A Political Argument for an Ethic of Care. New York: Routledge.

Tronto, J.C. (1998). An Ethic of Care. Generations, 22(3), 15.

Tronto, J.C. (2010) Ethics and Social Welfare Creating Caring Institutions: Politics, Plurality and Purpose, Ethics and Social Welfare, 4(2), 158-171. https://doi.org/10 $.1080 / 17496535.2010 .484259$

Tronto, J.C., \& Fisher, B. (1990). Toward a Feminist Theory of Caring. In E. Abel \& M. Nelson (Eds), Circles of Care (pp. 36-54). Albany, NY: SUNY Press.

Vaitheswaran,S.,Lakshimarayanan, M., Ramanujam,V., Sargunan,S., \&Venkatesan, S. (2020). Experiences and Needs of Caregivers of Persons with Dementia in India during the COVID-19 Pandemic: A Qualitative Study, The American Journal of Geriatric Psychiatry, 28, 1185-1194. https://10.1016/j.jagp.2020.06.026 